\title{
Contos de fadas da memória em Baú de ossos, de Pedro Nava
}

Maria Alice Ribeiro Gabriel ${ }^{1}$

O que chamamos Tempo - passado, presente, mesmo sua dimensão futura - é apenas fabricação da memória.

Pedro Nava

O que significa pensar uma narrativa literária no domínio da memorialística, integrada por outros discursos além daquele do historiador e da prosa autobiográfica? Essa questão é o ponto de partida deste artigo, que pretende discutir a alusão aos contos de fadas em Baú de ossos, obra do médico e escritor mineiro Pedro da Silva Nava.

A validade da memória ou testemunho enquanto fonte de reconstituição do passado é questão recorrente na historiografia, e a tentativa de delimitar seu campo de ação em um todo pertence a várias disciplinas com objetivos afins aos estudos literários.

Em suas Confissões (livro 10, cap. 8, 388), Santo Agostinho referiu-se aos "vastos palácios da memória", dedicando ao tema parte significativa de suas reflexões. Durante a passagem do século XVI ao XVII, em missão na China, o jesuíta Matteo Ricci desenvolveu técnicas mnemônicas que o tornariam célebre entre os eruditos confucionistas. Além de possuir extraordinária memória, Ricci dominava perfeitamente as antigas técnicas mnemônicas de Cícero e outros autores latinos, aperfeiçoadas por exegetas dos séculos XV e XVI. Sua inteligência multifacetada estendia-se aos campos da apologética, literatura, música, poesia e teologia. Entre seus biógrafos, destacou-se o historiador Johathan Dermot Spence, com $O$ Palácio da memória de Matteo Ricci (1984), que conecta o tratado sobre a memória elaborado pelo jesuíta "à sua notável compreensão da cultura chinesa e a sua atividade missionária".

Hanne Bewernick, em The storyteller's memory palace: a method of interpretation based on the function of memory systems in literature (2010), discutiu a aplicação dessas antigas teorias mnemônicas a textos narrativos de Geoffrey Chaucer, William Langland, Salman Rushdie, Angela Carter,

\footnotetext{
${ }^{1}$ Doutora em história social pela Universidade de São Paulo (USP), São Paulo, SP, Brasil. E-mail: rgabriel1935@gmail.com
} 
Thomas Pynchon e Paul Auster. Essas táticas de memorização, populares durante a Baixa Idade Média e a Renascença, a exemplo de "o palácio da memória" e "a jornada da memória", técnicas utilizadas na visualização de conceitos abstratos e na memorização de textos, uniam eloquência (filologia) e aprendizagem (as sete artes liberais) a fim de distinguir imagens materiais (rerum) de imagens para palavras (verborum). Bewernick (2010, p. 36) destacou a conexão peculiar entre narrativa e memória, visto que ambas dispõem imagens em uma estrutura ordenada: contar histórias reclama o ato da memorização. ${ }^{2}$

No primeiro volume das memórias de Nava, Baú de ossos (1972), há diferentes estratégias ou vozes narrativas que ressurgem em Balão cativo (1973), Chão de ferro (1976), Beira-mar (1978), Galo das trevas (1981), O círio perfeito (1983) e, indubitavelmente, no volume póstumo de Cera das almas (2006). São as vozes do compilador, do erudito, do esteta, do genealogista, do historiador e do médico. Entretanto, sem prescindir dessas vozes, Nava adotou um estilo literário peculiar para narrar alguns episódios da infância, identificando-os aos contos de fadas e contos populares. Ambos são amalgamados com histórias ouvidas na meninice: casos da esfera familiar, fatos ligados a Juiz de Fora, relatos históricos ou tocantes à memória coletiva.

A narrativa oral é reconstituída literariamente por elementos dos contos de fadas, mas, igualmente, da balada, da cantiga popular, da legenda e do folclore regional. Transcrita em relato biográfico-memorialista, reconstituise com aceitação da herança clássica, dialogando com Henrique de Huntingdon, François Villon e Walter Scott. Através da criação dessas alegorias autobiográficas, Nava transmite sua personalidade complexa com sensibilidade, humor e, tomando de empréstimo o termo a Harold Bloom, "dignidade estética".

Condensar recordações na forma de conto de fadas ou conto maravilhoso sugere outras possibilidades além do recurso poético. Gary

\footnotetext{
${ }^{2}$ Apesar de não ser inédito, o campo de pesquisa de Berwick é prolífico. No século XIX, por exemplo, através de enfoques diferenciados e originais, Charles Sanders Pierce, em Logic of relatives (1870), e Sigmund Freud em estudos como A interpretação dos sonhos (1899/1900), "Delírios e sonhos na gradiva de Jensen" (1907) e "Escritores criativos e devaneio" (1908), examinaram a afinidade entre a memória e a ordenação da linguagem e do pensamento. No século XX, Mahmoud Sami-Ali iniciou novas perspectivas sobre o estudo da memória a partir de L'espace imaginaire (1974). Gaston Bachelard, em A poética do espaço (1958) e, principalmente, em A poética do devaneio (1960), considerou o tema do devaneio em suas relações criativas com a infância, a linguagem e a memória.
} 
Weissman (2010, p. 139) sublinhou com justeza que, ao permitir à memória expressar-se diretamente a partir da infância, sem intervenção da censura consciente do adulto e do julgamento do escritor, a fantasia seria um meio de reformulação do passado. Reformulação que inclui a noção de topos. Segundo Bloom (1980, p. 399), topos seria, na verdade, menos um lugar-comum ou espaço da memória que o lugar de uma voz, lugar através do qual ressoa a voz dos mortos. Logo, topos seria a imagem de uma voz ou de um pronunciamento, ou o lugar onde uma imagem foi armazenada pela memória.

Este estudo inicia-se pela exposição da forma em que os contos de fadas são apresentados ao leitor por Nava, em seguida, faz algumas considerações sobre imagens, motivos ou temas postos em relação com tais narrativas e a infância do autor.

\section{“Tudo era uma vez..."}

A presença dos contos de fadas e dos contos populares nas memórias de infância de Nava é indissociável da efígie de seu principal narrador: Rosa de Lima Benta, entregue ainda criança à avó materna do autor, Dona Maria Luísa da Cunha Jaguaribe. “Não era preta de todo. Havia de ter sangue branco reescurecido por outras cruzas, mas que lhe deixaram aqueles extraordinários olhos que tinha - imensos e castanhoclaros, ambarinos, tirantes a verdes" (Nava, 1974, p. 238). Nos primeiros anos de casados, "o médico cearense dr. José Pedro da Silva Nava e a mineira D. Diva Mariana Jaguaribe" (Nava, 1974, p. 16) viveram entre o Rio de Janeiro e Juiz de Fora. Após a morte do marido, Dona Diva mudou-se com os filhos para a casa da mãe, em 1911. "Na Rua Direita 179 fomos recebidos pela Rosa" (Nava, 1974, p. 392). Nessa casa, nasceu a irmã caçula do autor e, com Dona Diva recuperando-se do parto, Nava tornou-se mais próximo de Rosa, que anteriormente já fora sua "bá". Luís da Câmara Cascudo fez uma descrição análoga à de Gilberto Freyre sobre a relação da ama negra com a criança:

No Brasil depressa a velha indígena foi substituída pela velha negra, talvez mais resignada a ver entregue ao seu cuidado a ninhada branca do colonizador. Fazia deitar as crianças, aproximando-as do sono com as estórias simples, transformadas pelo seu pavor, aumentadas na admiração dos heróis míticos da terra negra que não mais havia de ver. Dos elementos narrados pelas moças e mães brancas, as negras multiplicavam o material 
sonoro para a audição infantil. Humilde Sherazada, conquistava, com a moeda maravilhosa, um canto na reminiscência de todos os brasileiros que ela criava (Cascudo, 1984, p. 153).

Egbert Jan Bakker (1997 apud Purves, 2010, p. 37) identificou no discurso do poeta épico uma técnica especial da oralidade, desenvolvida no contexto performativo em que esse discurso é proferido diante de sua audiência. Essa técnica contribui para a convergência do passado e presente na narrativa do contador de histórias. Em sua formulação, o presente de Homero inclui o passado, de um modo diverso de nossa própria noção de uma nítida, espacial separação entre os tempos verbais. Alex C. Purves complementa a reflexão de Bakker afirmando que, através de certas marcas dêiticas, o poeta épico narra eventos remotos acercando-os ao presente imediato da audiência, tornando-a capaz de visualizar o passado próximo de sua percepção atual, no instante em que ouve as palavras do poeta.

O papel do tempo pretérito e da memória na poesia arcaica grega, dado que o ato de memorizar admitiria outros meios de figuração, seria tornar visível algo normalmente mantido oculto, ou seja, o testemunho ancestral dos feitos insignes de deuses e heróis.

Ao discorrer sobre as antigas teorias da enargeia, do prazer da poesia e de seu encantamento, mencionados por Hesíodo e Homero, Andrew Ford refere-se à "vivacidade" do épico ou ao senso de que o passado está de algum modo presentificado: "Chamarei de vivacidade, uma sensação de que o passado é de alguma forma presente diante de nós" (1992, p. 49 apud Purves, 2010, p. 38, tradução nossa). O narrador nato, imbuído do espírito das "crenças populares", especificou Walter Benjamin (1994, p. 216), pode, intuitivamente, dominar essas regras de "vivacidade" e "encantamento". Câmara Cascudo associou as amas de leite ou bás contadoras de histórias ao prazer de instruir e deleitar, funções primordiais do conto:

Essas amas de leite tiveram, na propagação, fixação e desdobramento dos contos africanos e portugueses, uma tarefa inconsciente e poderosa de acomodação à mentalidade do menino brasileiro e uma formação vocabulária curiosa, prosódia ameigada pelos timbres cheios de timidez e carinho, ensopados no leite da ternura humana (Cascudo, 1984, p. 153).

O "Era uma vez" dos contadores de história, declarou Ford (1992, p. 92), como a invocação do poeta épico, imediatamente prescreve a questão da transmissão, ao postular um encadeamento descendente das 
musas ao poeta e deste para a audiência. Areti Dragas (2014, p. 13) comparou o contador de histórias à criança de imaginação romântica, alguém constante através das eras, desde o nascimento do homem, uma figura arcaica. Ele performatiza o ato de narrar e, inerente à palavra "estória" reside a noção de invenção ou mentira, noção que conduz a questões sobre verdade e ficção. Essa função "arcaica" de rapsodo e guardião do passado, segundo Dragas, é uma de suas imagens mais persistentes na cultura moderna, condizente ao seguinte excerto de Nava:

Mas o melhor é que a Rosa, além de ser um canhenho vivo, sabia, ouvidas não sei onde nem de quem, todas as histórias de Andersen, Perrault e dos irmãos Grimm. Devo a ela as da Sereia menina, do Rouxinol, do Patinho Feio e dos Cisnes Bravos... Do Gato de Botas, do Barba Azul e do Chapeuzinho Vermelho... Da Borralheira, do Pequeno Polegar e da Branca de Neve... Todas as noites, na hora de deitar... Rosa! Agora a Pele de Burro. Agora a Bela e a Fera. E vinham as histórias (Nava, 1974, p. 239).

O contato inicial de Nava com os contos de fadas não foi uma experiência vivenciada pela leitura, mas enriqueceu-a, conforme pretendemos demonstrar a seguir.

\section{"E se não morreram vivem até hoje"}

Em O narrador: considerações sobre a obra de Nikolai Leskov (1936), ao mensurar a importância do contador de histórias na preservação e transmissão da memória cultural, sua função integral nas comunidades e presença contínua através da história, Benjamin discerniu um fenômeno característico dos séculos XX e XXI - a incapacidade de atribuir sentido à experiência individual: "No final da guerra, notou-se que os combatentes voltavam mudos do campo de batalha, não mais ricos, e sim mais pobres em experiência comunicável" (Benjamin, 1994, p. 198). No tempo em que as pessoas recebiam a informação localmente, anterior às duas Grandes Guerras, as ações de contar e de ouvir histórias proporcionariam à audiência o enriquecimento da percepção subjetiva de si e do outro, bem como da "faculdade de intercambiar experiências".

Uma das ponderações de Walter Watson sobre o efeito catártico atribuído por Aristóteles à poesia trágica outorga à catarse o encargo de remover algo da alma, mais que do corpo: "O genus da catarse trágica é a remoção de algo da alma e não do corpo" (Watson, 2012, p. 142, tradução 
nossa). A acepção da palavra "remoção", utilizada pelo autor, inclui o sentido de eliminar algum tipo de passio negativa da alma, tanto quanto o de extrair da alma um significado para o que está em evidência na poesia.

Bruno Bettelheim julgou necessário iniciar seu estudo A psicanálise dos contos de fadas (2002) discorrendo justamente sobre "a luta pelo significado" envolvida no relato do conto de fadas, maravilhoso ou popular. Assim, através do relato na forma de conto de fadas, Nava apresentaria ao leitor de suas memórias não um enfoque trágico, mas lúdico e poético, condizente com o universo infantil da fantasia, do inverossímil e maravilhoso. Porém, nas passagens envolvendo pessoas e fatos marcantes da infância, o trágico ainda permanece acessível, análogo ao conteúdo latente da elaboração onírica:

Nosso primo Antonico Horta, por exemplo, com suas ameaças de virar criança pelo avesso, era certamente um bruxo. [...] Mas sua traça mais terrível era praticada com seu xará, também primo, o Antonico Pinto Monteiro. Este morava num palacete cheio de torres e minaretes com cúpulas revestidas de lâminas de prata. Tinha da prima Nicota duas filhas, a Noite e a Aurora. Eram gêmeas. Uma era branca e clara, radiosa e loura, olhos azuis como céus matutinos. Outra era bronzeada e escura, radiante e morena, olhos negros como mares noturnos. Quando eu cruzava a Rua direita, olhava sempre, da esquina, os altos da Rua do Imperador. Às vezes o palacete estava lá, rente ao morro e as gêmeas cantavam. Doutras, tinha sumido, estava em Matias, no Rio, em Pasárgada, em Samarcanda, na Mongólia, para onde o transportara o Antonico Horta que passara disfarçado e comprara da prima Nicota a Lâmpada Mágica que Aladino deixara para as duas meninas. Logo o Antonico Pinto Monteiro com astúcias mil ia à Rua Espírito Santo, recuperava a Lâmpada da Prima Marieta e da Dona Rafaela, fazia o Gênio aparecer e devolver seu palacete à Rua do Imperador. Com móveis, pratas, alfaias, bragais, palmeiras, pavões, cascatas e as duas gêmeas: uma de ônix e a outra de turquesa. Quando eu via juntos os dois Antonicos, rindo e galhofando, pasmava daquela hipocrisia. Já era cinismo, para dois primos que viviam em luta pela lâmpada maravilhosa (Nava, 1974, p. 240-1).

A questão patrimonial entre os primos homônimos, que formam uma espécie de doppelgänger da ambição, conserva sua própria unidade, enriquecida pela descrição das gêmeas, Noite e Aurora, evocação dos amores de Ivanhoé: a bela judia Rebeca e Lady Rowena; por cenas 
românticas de damas aprisionadas em torres "com cúpulas revestidas de lâminas de prata" e a menção de espaços exuberantes: "em Matias, no Rio, em Pasárgada, em Samarcanda, na Mongólia", enumerados em uma gradação imagética que vai da realidade à fantasia, referências ao Oriente exótico da literatura oitocentista. O luxo do palacete da Rua do Imperador compara-se à magnificência de um cenário de As mil e uma noites: "Com móveis, pratas, alfaias, bragais, palmeiras, pavões, cascatas e as duas gêmeas: uma de ônix e a outra de turquesa." Essa profusão de imagens adquire semântica mais refinada, intensificada nas passagens envolvendo assuntos de família.

Para comentar o próximo excerto são necessárias algumas considerações, a saber: cresmólogo é um especialista em interpretação dos sinais divinos. O filósofo André Neher fez ressaltar a distinção entre o profeta bíblico e o cresmólogo, recordando que o primeiro é um profeta coletivo, homem do povo similar ao funcionário ou ao sacerdote. No caso do profeta bíblico, este apresenta um componente claramente plebeu e, ao contrário do cresmólogo, não pertence ao anonimato. Enquanto o profeta bíblico interessa tanto por seu ensinamento quanto por sua mensagem, o cresmólogo assemelha-se, segundo a expressão de Bouché-Leclercq (p. 92 apud Neher, 1984, p. 46), a um desfile de fantasmas. Ele é um indivíduo obscuro, distanciado da plebe pelo estatuto aristocrático de profeta individual e tem oráculo próprio (Neher, 1984, p. 38).

Justo Florian Lobeck (1862, p. 649) usou a expressão "maniobras $i$ cavilaciones místicas" citando o cresmólogo ou vaticinador Onomácrito, natural de Atenas, assinalado por Herédoto como instrumento político do tirano Pisístrato. Entre suas "maniobras", aparentemente teria falsificado os oráculos de $\mathrm{Museo}^{3}$ para fins políticos, pois muito amiúde se fez na Antiguidade uso de oráculos forjados. $O$ mencionado Onomácrito instituiu consagrações secretas a Baco por um ritual místico, e para lhes dar crédito, falsificou canções e poesias de Orfeu atribuindo-as ao deus do vinho. Descrição semelhante esboça o perfil do marido de Maria Berta Halfeld Paletta, tia materna de Nava:

Pior ainda era o Paletta. Cresmólogo, cabalista, necromante, ele conseguira levantar em torno de sua casa da Rua de Santo Antônio uma floresta toda de aço onde pastavam dragões verdes

\footnotetext{
${ }^{3}$ Houve homens que se empenharam em fazer recompilações das respostas dos oráculos, entre as mais famosas, as que formaram Bacis e Museo - considerado discípulo de Orfeu (Castro, 1789, p. 483).
} 
vomitando chamas. Dois cães infernais montavam guarda sobre as pilastras do portão. Só minha Mãe tinha o poder de petrificar os dois cachorros, que viravam cimento à sua passagem, enquanto as urzes de metal se abriam numa aleia de espinheiro bastardo e ela, com seu guarda-chuva mágico, lanceava os dragões ardentes que, a esse toque, caíam mortos na forma de simples taturanas. Toda essa maldade do Paletta era para prender a mulher e as filhas. Libertava-as a visitação de Inhá Luísa e de minha Mãe. Aí o Bicanca trancava-se no escritório com seus alambiques e mal elas saíam, que ele com seus sortilégios repunha em torno da casa os dois grandes cães estilitas, os ígneos dragões e a floresta de ferro com suas flores de cheiro mortal. Que o Paletta tinha parte, lá isso tinha. A prova é que anos mais tarde, ele estando em período de reinação, minha tia aproveitou seu sono para aspergi-lo com água-benta. Conselho do Padre Leopoldo Pfad. Pois onde bateram as gotas de Deus, o exorcismado ficou todo empolado. O Dr. Rubens Campos, incréu, disse que era alergia (Nava, 1974, p. 241).

Maria de Fátima Silva sintetizou a reflexão de Emilio Suarez de La Torre sobre os adivinhos e sua atividade no contexto da comédia de Aristófanes, em que se destaca a análise da forma e conteúdo da expressão oracular relacionada às suas convenções:

Suarez de La Torre sistematiza uma série de testemunhos que sujeitam o mundo da adivinhação a um processo satírico que provém já da poesia iâmbica, de que, também neste aspecto particular, a comédia se mostra herdeira. Retocado pela própria experiência do séc. $V$, o tipo tradicional concretiza-se no cresmólogo ou profeta oportunista e falso, mas com um efetivo poder de intervenção social e política (Silva, 2000, p. 352).

O advogado Constantino Luís Paletta é presença muito forte na memorialística de Nava e está vinculado à história social e política de Juiz de Fora: "Seu prestígio era tal que não só foi ministro, como fez ministro seu amigo Fernando Lobo, que Floriano nunca tinha enxergado" (Nava, 1974, p. 284). O Bicanca, assim chamado em família, somente em Baú de ossos possui vários retratos literários, do cômico ao dramático, passando pelo lúdico e fantasioso, mas nenhum exposto sem uma nota de consternação:

Não sei se teria sido amigo de meu Pai ou se servia-se de sua bondade e boa-fé, para tirar sardinha com a mão do gato. As 
verrinas de imprensa contra o Antônio Carlos, ${ }^{4}$ por exemplo, eram escritas por meu Pai, mas geralmente inspiradas pelo Bicanca. Bom advogado, falando fluentemente, um dos fundadores, em 1883, do Clube Republicano Mineiro, republicano histórico e deputado à primeira Constituinte - o Paletta, em Juiz de Fora, chegara, vira e vencera (Nava, 1974, p. 283-284).

Henrique de Beauclair, inversamente à imagem de Paletta, está envolto por uma aura de ternura e deferência. $\mathrm{O}$ médico foi companheiro de José Pedro da Silva Nava na Sociedade de Medicina e Cirurgia de Juiz de Fora, onde o pai de Nava secretariou com Cristóvão Malta, de 1904 a 1907 (Nava, 1974, p. 278). Dr. Beauclair assistiu a "Cirurgia de 1905" de Alice de Luna Freire: "Vulto indistinto e que é um dos fantasmas amáveis da minha infância" (Nava, 1974, p. 234). Alice morreu devido a uma apendicite supurada que "terminou em septicemia e morte. [...] A operação foi na nossa sala de jantar, a menina deitada numa escrivaninha, anestesiada a cloretila por meu Pai" (Nava, 1974, p. 233-234). O corpo de Alice permaneceu insepulto por quase dois anos:

Todo esse ambiente solene do quarto, seu tom de tristeza e seu cheiro a cera e sacristia vinham do fato de estarem no baú do oratório os ossos de minha prima Alice - morta em Juiz de Fora. Coubera a meu Pai exumá-los, lavá-los, trazê-los para o Rio e entregar à irmã a bagagem terrível (Nava, 1974, p. 363).

Dr. Beauclair é uma das imagens paternais de Baú de ossos, amigo e médico da família, morador do número 160 da Rua Direita: “Nasci nessa rua, no número 179, no sobrado onde reinava minha avó materna" (Nava, 1974, p. 13). A memória de sua presença não se restringe às circunstâncias da morte trágica de Alice e a essência de seu caráter benevolente está condensada na cena alusiva à história de Branca de Neve:

Gênio bom era o Doutor Beauclair. Diziam que era médico e era mesmo, por sinal que médico de meu irmão Paulo. Instruído pelas histórias da Rosa, eu sabia, apesar de sua estatura, que ele era um dos sete anões da Branca de Neve. Na janela, sua cara ficava da altura do peitoril, de onde descia até a rua a catadupa de suas barbas. Vinham da face onde as maçãs tinham mesmo forma e consistência de fruta. Vinham da face rubicunda, vinham e desciam até o chão, como colchas penduradas em dia de festa.

${ }^{4}$ Sobre Antônio Carlos Ribeiro de Andrada, sua família e carreira política, ver Nava (1974, p. 282-283). 
$\mathrm{Eu}$, quando passava em sua casa, descrevia um semicírculo cauteloso para não me emaranhar naquela floresta. Ele ria e eu arriscava um olho pela porta aberta, para ver se via o ataúde de cristal da Branca de Neve. Quando ele saía à rua, botava corpo e virava médico outra vez (Nava, 1974, p. 241).

O episódio sobre Carmem Sílvia Paletta de Rezende Tostes (Mimi), filha de Maria Berta e Constantino Luís Paletta, é narrado com menção às novelas de cavalaria e "courtoisie", ao conto de fadas e, notavelmente, ao Ciclo arturiano ou Matter Britain. A história e a legenda do rei Cnut constam das crônicas da Historia Anglorum (1140), escrita pelo historiador medieval Henrique de Huntingdon, um século após a morte do rei. Segundo a lenda King Canute and the waves, Cnut, então senhor da Dinamarca, Escócia, Inglaterra e Noruega, teria concedido a mão de sua filha ao imperador romano. Nava expõe, em primeiro plano, a história de Mimi, em consonância à do ambicioso rei:

Mas linda, linda era a história da Mimi Canuto. Era filha dum soberano do Norte chamado Knut ou Canuto, que andava em Juiz de Fora encantado de advogado. Quando ela passava do outro lado da rua, o ar lamentável e dois bandós saindo do rugerone como as orelhas dum poodle, as araras do parque Halfeld gritavam de dor com a mágoa da princesa. Minha Mãe anunciava da janela que lá ia a Mimi Canuto, coitada... (Nava, 1974, p. 242).

A crônica de Huntingdon narra a história de Cnut contando três de seus finos e magnificentes feitos, "fine and magnificent deeds", enfatizando que, antes dele, nunca houvera, em toda Inglaterra, rei com tal autoridade. O último desses feitos deu origem à legenda apócrifa. Assim, um dia, o rei Cnut determinou que seu trono fosse levado até a praia e deixado ao alcance da maré. Então, ele ordenou às ondas que se erguiam:

Vós estais sob o meu domínio, como a terra em que estou sentado me pertence, e ninguém há resistido ao meu poderio impunemente. Ordeno-vos, portanto, não avanceis sobre minha terra, nem vos atrevais a molhar as vestes ou o corpo de vosso senhor (Huntingdon, 1996, p. 367, tradução nossa).

Mas o mar avançou indiferente e encharcou os pés de Cnut. Saltando para trás o rei bradou: "Saiba o mundo inteiro que o poder dos reis é vazio e insignificante, e não existe rei digno desse nome salvo Aquele, por cuja autoridade, firmamento, terra e mar obedecem às leis eternas 
(Huntingdon, 1996, p. 367, tradução nossa). Segundo a crônica, destarte o rei Cnut retirou sua coroa e a depositou na cabeça do Senhor crucificado, e nunca mais voltou a usá-la, em gesto de eterna prece e reverência a Deus, o grande rei. Essa passagem proverbial foi absorvida pelo imaginário inglês como relato exemplar sobre a vitória da devoção e da humildade sobre a insensatez da presunção.

Nava parece ter entremeado a narrativa de Mimi Canuto à crônica histórica de personalidades de sua família e de influentes famílias mineiras:

O Rei Canuto de Figueiredo morava no Alto dos Passos e depois de viúvo tomara como nova esposa a Iaiá do seu Chico Brandt, que foi coroada rainha com o nome de Dona Maria do Carmo Brandt de Figueiredo e que, para mostrar poderio, logo fez o pai Comendador. Aleivosamente a madrasta induziu Mimi a entrar numa banheira cheia de sapos. Sapo, meu sapo encantado, cola-te à testa de Mimi e fá-la tão tola quanto és. Sapo, meu sapo encantado, cola-te à face de Mimi e fá-la tão horrenda quanto és. Sapo, meu sapo encantado, cola-te ao corpo de Mimi e fá-la tão disforme quanto és. Mas a sombra de uma lágrima da mãe defunta imobilizou os sapos e Mimi continuou espirituosa, bela, elegante e mais mimi do que nunca. Então a Iaiá furiosa enterrou a enteada debaixo dum pé de figueira. Seus cabelos cresceram feito um capinzal todo verde que cantava de tarde pedindo ao capineiro-demeu-pai que não os cortasse e às aves que fossem chamar seu noivo. Foram. Ele veio correndo do Alto dos Passos com seus dois irmãos. Quanta laranja madura - quanto limão pelo chão - quanto sangue derramado dentro do meu coração! O primeiro era o Luís, o segundo o Raul, o terceiro foi aquele a quem ela deu a mão. Chamava-se Fernando Pena e mandou que os três sapos grudassem na cabeça da sogra torta e chupassem-lhe os miolos. Por isso ela acabou dementada e presa nos subterrâneos da casa do Rei Canuto. A Princesa Mimi foi para Belo Horizonte com o Príncipe Fernando Pena, que lá viveu encantado de advogado, do mesmo jeito que o sogro em Juiz de Fora (Nava, 1974, p. 242).

Carmem Ś́lvia Paletta casou-se com João de Rezende Tostes (Nava, 1974, p. 165). O "seu Chico Brandt" trata-se, possivelmente, de Francisco Eugênio Brandt Horta, jornalista, músico e poeta, fundador da cadeira 10 da Academia Brasileira de Letras, "que a prima Mariquinhas nunca chamava simplesmente de 'Chico' ou de 'meu filho'. Tinha de ser aquele inseparável Chicomeufilho" (Nava, 1974, p. 239). Constantino Luís Paletta 
manteve escritório de advocacia em Belo Horizonte associado a Feliciano Pena (Abreu, 2001; Diniz, 1943, p. 40). João de Rezende Tostes também advogava em Belo Horizonte. A narrativa enseja, pois, o jogo de "esconde e revela" sobre a identidade das personagens, o que vale para o "Príncipe Fernando Pena", "Dona Maria do Carmo Brandt de Figueiredo" e "o pai Comendador", lembrando que Henrique Guilherme Fernando Halfeld, primeiro marido da avó materna de Nava, recebera o título de comendador e teve um filho chamado Fernando Feliciano Halfeld, de sua primeira mulher Dona Doroteia Augusta Filipina (Nava, 1974, p. 131).

"A Moura Torta", "A menina enterrada viva" e seu canto - "Capineiro de meu pai / não me cortes os cabelos / minha mãe me penteou / minha madrasta me enterrou" - foram coletados nos Contos tradicionais do Brasil, de Câmara Cascudo (1999). Pela "sombra de uma lágrima da mãe defunta" que desfaz o poder das trevas, é possível entrever a mãe ausente, mas protetora, de Cinderela. O noivo chamado em auxílio da dama em perigo, "do Alto dos Passos com seus dois irmãos", recorda a última cena do conto "O Barba Azul", tanto quanto a "Iaiá furiosa", a "sogra torta", rivaliza em maldade com a moura invejosa, e cujo fim lembra outra imagem do ciúme, Joana de Espanha, a Louca. Por fim, a cantiga do romanceiro português, "Terezinha de Jesus", justamente pelo tom jocoso do autor, projeta em Mimi o destino imposto à dama da balada irlandesa "The Lass of Aughrim", para Harry White (2008, p. 157), "a música distante" - e seu poder de despertar aquelas memórias do amor perdido - que atribui significado à história de Gabriel Conroy, em "Os mortos" (1914), de James Joyce.

Nava encerra esse "capítulo" de suas memórias contando seu reencontro com Rosa, já adulto, médico, vivendo no Rio de Janeiro: "Anos depois ela me descobriu na Rua da Glória e veio me visitar. Estava gorda, mãe de família e dera para beber. Só que tinha a mesma constelação antiga das estrelas dos olhos e da estrela da face" (Nava, 1974 , p. 243). Mas o atributo final desse capítulo, que termina com uma evocação a Ballade des dames du temps jadis, de François Villon, não é a alegria e sim a nostalgia: "Mas onde estavam, onde? as floresd'antanho" (Nava, 1974, p. 244).

Nava extraiu de um episódio familiar de luto o título para abrir o projeto de suas memórias - o longo curso da melancolia da irmã de seu pai, Cândida Nava de Luna Freire, após a morte da filha Alice, "até que 
minha tia mandasse erguer, sobre o túmulo do marido, a caixa de mármore para que passou o esqueleto" (Nava, 1974, p. 363):

E teria ela, na solidão e na saudade de suas noites de insônia, resistido à tentação mórbida de abrir aquele baú, de tocar naqueles ossos despojados, na caveira decomposta e de explorar a distância milimétrica e imensa que vai de nós ao não ser tangível? De que tentamos guardar a forma nos objetos-relíquia usados pelos nossos mortos, em sua vida, ou nas flores do seu caixão, ou nos seus retratos, ou nos seus cabelos. Ou ficando logo com o defunto em casa ou um pouco deles - tais a amada inteira! Enterrada sob o leito ou o crânio viajor embrulhado no lenço vermelho - como está em A Noite na Taverna (Nava, 1974, p. 363).

O propósito de contar uma boa história tem encontrado todo tipo de teorização desde 1900. Possivelmente, talvez em um futuro bem próximo, poucas sejam lembradas, mas a necessidade imutável de atribuir sentido à própria existência permanecerá. Ao finalizar seu estudo "Luto e melancolia", um ano após o início da Primeira Guerra, Freud preferiu não apresentar conclusões definitivas sobre a "natureza econômica, primeiro da dor física, depois da dor mental, análoga a ela", afirmando: "Conforme já sabemos, a interdependência dos complicados problemas da mente nos força a interromper qualquer indagação antes que esteja concluída - até que o resultado de uma outra indagação possa vir em sua ajuda" (Freud, 1996, p. 291). O momento que prometia um grande apogeu cultural dissipava-se na estagnação. A Belle Époque extinguia-se com o início da era do declínio da arte de narrar e a perda da capacidade de intercambiar experiências, detectada por Benjamim. O último episódio de Baú de ossos data de 1911 e apreende essa transição preservando a tradição dos grandes narradores.

Todos os princípios e variações que formam a retórica dos contos de fadas em Baú de ossos poderiam fundir-se em um oximoro. A ficção e a história, a inocência e a ironia, a perspectiva da criança e a do adulto, a tentativa de elaboração do sofrimento e a celebração do que o Papa emérito Joseph Ratzinger denominou "a experiência da bondade dadivosa da existência" perfazem um delicado equilíbrio.

Os retratos humanos obedecem a esse mesmo fundamento, sem incorrer em traços caricaturalmente redutores ou maniqueístas: o médico alto e gentil é, na verdade, um dos anões de Branca de Neve; o tio "que tinha parte" também pode viver "encantado de advogado" 
com o genro e ser magnânimo na humilhação como o "Rei Canuto", do mesmo modo que "os dragões ardentes" "caíam mortos na forma de simples taturanas".

A memorialística é um gênero labiríntico, de recordações históricas e ficcionais. Jacques Le Goff admitiu que "Paul Veyne estabeleceu uma visão original da história. Para ele a história é um conto, uma narração, mas "um conto de acontecimentos verdadeiros'" (Veyne, 1971, p. 16 apud Le Goff, 1996, p. 39). Assim, ela interessar-se-ia por uma forma particular de singularidade, de individualidade, que é o específico, "por acontecimentos individualizados dos quais nenhum é a inútil repetição do outro, mas não é a sua individualidade enquanto tal que a interessa" e sim compreendê-los, reencontrando neles certa espécie de generalidade ou especificidade. "A história é a descrição do que é específico, isto é, compreensível, nos acontecimentos humanos" (Veyne, 1971, p. 73-5 apud Le Goff, 1996, p. 39).

“William Dray definiu a 'representação imaginativa' do passado como uma forma de explicação racional" (Dray, 1957 apud Le Goff, 1996, p. 39). Conforme Dray arguiu em History as reenactment (1999) sobre os aspectos epistemológicos da teoria da história, recriar elementos de um evento ou período através da memória supõe repensar profundamente as noções de passado, história e temporalidade. A memória enquanto fonte e matéria de especulação é uma indagação permanente para a historiografia.

Após o Holocausto, o valor do testemunho foi repensado e Dominick LaCapra (1998, p. 11) considerou-o fonte crucial para a história, mais que uma fonte, um desafio: "O testemunho é uma fonte crucial para a história. Mais que uma fonte, ele impõe desafios singulares à história." A fusão entre testemunho e ficção não ficaria assim restrita ao campo da literatura. Conforme Carla Dente (2015, p. 193) notou, a realidade preexiste ao testemunho em si mesmo, mas, paradoxalmente, é incapaz de estabelecer a si mesma se não for autenticada pelo testemunho.

O relato memorialístico é constituído por inúmeras possibilidades de investigação, guardadas suas relações com o conto, a crônica, o drama, o ensaio e a poesia, e pode apropriar-se ainda de outros códigos complexos de expressão e objetos da realidade na criação de mundos ficcionais ou na preservação do tempo passado. 


\section{Referências}

ABREU, Alzira Alves (Coord.) (2001). Dicionário histórico-biográfico da Primeira República (1889-1930). Rio de Janeiro: FGV.

BENJAMIN, Walter (1994). O narrador: considerações sobre a obra de Nikolai Leskov. In: BENJAMIN, Walter. Magia e técnica, arte e política: ensaios sobre literatura e história da cultura. Tradução de Sérgio P. Rouanet. São Paulo: Brasiliense, p. 197-221.

BETTELHEIM, Bruno (2002). A psicanálise dos contos de fadas. Rio de Janeiro: Paz e Terra.

BEWERNICK, Hanne (2010). The storyteller's memory palace. Frankfurt: Peter Lang.

BLOOM, Harold (1980). Wallace Stevens: the poems of our climate. Ithaca; London: Cornell University Press.

CASCUDO, Luís da Câmara (1984). Literatura oral no Brasil. Belo Horizonte: Itatiaia.

CASCUDO, Luís da Câmara (1999). Contos tradicionais do Brasil. Rio de Janeiro: Ediouro.

CASTRO, Francisco de (1780-1789). Dios y la naturaleza. Compendio histórico, natural, y político del universo, en que se demuestra la existencia de Dios, y se refiere la historia natural y civil, la religión, leyes, y costumbres de las naciones antiguas, y modernas más conocidas del Orbe. Madrid: Joachin Ibarra, $10 \mathrm{v}$.

DENTE, Carla (2015). Reality, theatre and human wrights. In: WARD, Ian (Ed.). Literature and human rights: the law, the language and the limitations of human rights discourse. Berlin; Munique; Boston: De Gruiter, p. 183-195.

DINIZ, Alberto (1943). Vida que passa: memórias. Rio de Janeiro: Imprensa Nacional, 1943.

DRAGAS, Areti (2014). The return of storyteller in contemporary fiction. London: Bloomsbury.

FORD, Andrew (1992). Homer: the poetry of the past. Ithaca; London: Cornell University Press.

FREUD, Sigmund (1996). Luto e melancolia. In: FREUD, Sigmund. Edição standard brasileira das obras psicológicas completas de Sigmund Freud. Rio de Janeiro: Imago, v. XIV, p. 271-291. 
HUNTINGDON, Henry (1996). Historia anglorum: the history of the English people. Edited and translated by Diana Greenway. Oxford: Clarendon Press. (Oxford Medieval Texts).

LACAPRA, Dominick (1998). History and memory after Auchwitz. Ithaca: Cornell University Press.

LE GOFF, Jacques (1996). História e memória. Campinas: Editora da Unicamp.

LOBECK, Justo Florian (1862). Ojeada retrospectiva sobre la marcha que, desde los tiempos antiguos hasta nuestros dias, se ha seguido al tratar de la mitolojía clásica. Anales de La Universidad del Chile, Santiago, tomo 21, serie 1, p. 633-655.

NAVA, Pedro (1974). Baú de ossos. Rio de Janeiro: José Olympio.

NEHER, André (1984). L'essenza del profetismo. Genova: Marietti.

PURVES, Alex C. (2010). Space and time in ancient Greek narrative. New York: Cambridge University Press.

SILVA, Maria de Fátima; J. A. LÓPEZ FÉREZ (Ed.) (2000). La comedia griega y su influencia en la literatura española, Madrid, Ed. Clásicas, 1998. Resenha. Humanitas, Coimbra, v. 52, p. 350-355. Disponível em: https://goo.gl/u2yHXx. Acesso em: 28 nov. 2015.

WATSON, Walter (2012). The lost second book of Aristotle's "poetics". Chicago: University of Chicago Press.

WEISMANN, Gary (2010). Questioning key texts: a pedagogical approach to teaching Elie Wiesel's Night. In: BLOOM, Harold (Ed.). Elie Wiesel's Night. New York: Infobase Publishing, p. 137-46.

WHITE, Harry (2008). Music and Irish literary imagination. New York: Oxford University Press.

Recebido em janeiro de 2016.

Aprovado em julho de 2016.

\section{resumo/abstract/resumen}

\section{Contos de fadas da memória em Baú de ossos, de Pedro Nava}

Maria Alice Ribeiro Gabriel

Situada em relação à problematização pós-moderna do conhecimento histórico, a prosa memorialística, mesmo se transformada em arte, tem sido descrita em 
relação à memória, mais que em relação à história. Baseado em um criticismo biográfico e histórico, este artigo pretende discutir a presença dos contos de fadas nos escritos de Pedro Nava sobre suas memórias de infância em Baú de ossos (1972) e expor como esses relatos são estruturados pelos discursos autobiográfico e ficcional.

Palavras-chave: conto de fadas, história, memória, Pedro Nava.

\section{Fairy tales of memory in Baú de ossos by Pedro Nava}

Maria Alice Ribeiro Gabriel

Situated in relation to a postmodern problematization of historical knowledge, memorialistic prose, even when transformed into art, has been described in relation to memory, rather than history. Based on a biographical and historical critical approach, this essay intends to discuss the presence of fairy tales in Pedro Nava's writings about his childhood memories in Baú de ossos (Trunk of bones, 1972), attempting to expose how these accounts are determined by autobiographical and fictional discourses.

Keywords: fairy tales, history, memory, Pedro Nava.

\section{Cuentos de hadas de la memoria en Baú de ossos, de Pedro Nava}

Maria Alice Ribeiro Gabriel

Situada en relación a la problematización posmoderna del conocimiento histórico, la prosa memorialística, aunque transformada en arte, ha sido descrita en relación a la memoria más que en relación a la historia. Basado en un criticismo biográfico y histórico, este artículo pretende discutir la presencia de los cuentos de hadas en los escritos de Pedro Nava sobre sus recuerdos de infancia en Baú de ossos (Baúl de huesos, 1972) y exponer cómo esos relatos son estructurados por los discursos autobiográfico y ficcional.

Palabras clave: cuentos de hadas, historia, memoria, Pedro Nava. 